\begin{tabular}{|c|c|}
\hline Title & Self-healing A bility of Conductive Poly pyrrole Coating with A rtificial Defect \\
\hline Author(s) & Kowal ski, Damian; Ueda, Mikito; Ohtsuka, Toshiaki \\
\hline Citation & $\begin{array}{l}\text { ECS Transactions, 16(52), 177-181 } \\
\text { https://doi.org/10.1149/1.3229965 }\end{array}$ \\
\hline Issue Date & 2009 \\
\hline Doc URL & http:/hdl.handle.net/2115/60231 \\
\hline Rights & $\begin{array}{l}\text { (1) The Electrochemical Society, Inc. 2009. All rights reserved. Except as provided under U.S. copyright law, this work } \\
\text { may not be reproduced, resold, distributed, or modified without the express permission of The Electrochemical Society } \\
\text { (ECS). The archival version of this work was published in ECS Transactions, V olume 16, Issue 52, pp. 177-181, } 2009 .\end{array}$ \\
\hline Type & article \\
\hline File Information & OhtsukaECS16(52-177).pdf \\
\hline
\end{tabular}

Instructions for use 


\title{
Self-healing Ability of Conductive Polypyrrole Coating with Artificial Defect
}

\author{
Damian Kowalski, Mikito Ueda, and Toshiaki Ohtsuka \\ Graduate School of Engineering, Hokkaido University, Sapporo 060-8628, JAPAN
}

A bi-layered PPy film consisting of an inner layer doped with Keggin-structure anions of $\mathrm{PMo}_{12} \mathrm{O}_{40}{ }^{3-}$ and $\mathrm{HPO}_{4}{ }^{2-}\left(\mathrm{PPy}^{-} \mathrm{PMo}_{12}\right)$ and an outer layer doped with organic anions of dodecyl sulfate (PPy-DoS) exhibited a self-healing property when coated on steel. When a defect was introduced into the PPy-coated steel immersed in $3.5 \% \mathrm{NaCl}$ aqueous solution, the potential initially decreased and activation of the coated steel occurred. After a few hours, the potential was recovered to the passive region, and the passivation continued for another 20 hours. Without any damage, the release of $\mathrm{PMo}_{12}$ doped in the inner layer was inhibited by the outer PPy layer doped with DoS. When a defect was introduced into the PPy film, the inner PPy layer released phosphate and molybdate anions to the damaged zone due to their decomposition via hydrolysis. Both anions work as passivation inhibitors and helped to repassivate the damaged zone on the steel.

\section{Introduction}

Throughout the anticorrosion industry, pigmentation of conventional polymers such as epoxy resin with chromates $\left(\mathrm{CrO}_{4}{ }^{2-}\right)$ is used to provide corrosion protection for steels. Although chromate-based coatings are very effective for corrosion protection, their use will be strictly restricted due to negative environmental and health aspects $(1,2)$. Conductive Polymers (CPs) such as polypyrrole (PPy) and polyaniline (PANI) have been considered candidates to replace chromates because their oxidative and catalytic properties induce a stable passive state in steels $(3,4)$. Although the mechanism of corrosion protection by CPs is not fully understood, there have been many studies confirming the existence of an oxide film at the metal-polymer interface. The oxide film is assumed to be formed due to interaction between the polymer and metal substrate. The nature of the oxide film may strongly depend on the type of polymers and counter-anions doped into the polymer matrix (4-8).

In our approach to the study of PPy we assumed that the counter-anions contribute to the formation of a stable passivation oxide film at the metal-polymer interface. Molybdophosphate, $\mathrm{PMo}_{12} \mathrm{O}_{40}{ }^{3-}\left(\mathrm{PMo}_{12}\right)$, a Keggin-structure anion used as the doped counter-anion in PPy in this study, plays the role of passivation inhibitor for steels and facilitates the passivation of steels covered by PPy. However, since the Keggin-structure anions are not stable in a neutral $\mathrm{pH}$ solution, they decompose into smaller anions, resulting in dedoping of the counter-anions from PPy and significant loss in protection efficiency (9). To inhibit the dedoping process of decomposed forms of $\mathrm{PMo}_{12} \mathrm{O}_{40}{ }^{3-}$ an outer layer doped with dodecyl sulfate (DoS) has been introduced (10). The bi-layered coating system of PPy-PMo ${ }_{12} / \mathrm{PPy}-\mathrm{DoS}$ exhibited significant improvement of corrosion protection in $\mathrm{NaCl}$ aqueous solution. Since the outer layer doped with DoS possesses a cation-exchange property, the migration of aggressive $\mathrm{Cl}^{-}$ions to the PPy film is greatly restricted (11). High oxidizing capability connected with the cationic permselectivity 
allows the steel to remain in a passive state for long time period in $\mathrm{NaCl}$ aqueous solution $(10,11)$.

In this study, we present the self-healing property of this bi-layered PPy coating. Specifically, we report the recovery of passivation of the coated steel in $\mathrm{NaCl}$ aqueous solution after a defect has been created in the coating.

\section{Experimental}

Pyrrole monomer (Py) purchased from Kanto Chemical Co. (99\% purity) was used without any pretreatment. All the other reagents were purchased at analytical grade from Wako Pure Chemical Ltd. Solutions used were prepared from double distilled and subsequently deionized Milli-Q water, and deoxygenated by nitrogen bubbling for $30 \mathrm{~min}$ before use. Carbon steel with the composition of C 0.032, Si 0.013, Mn 0.15, P 0.012, S $0.008, \mathrm{Al} 0.018$ and Fe 99.767 wt. \% was mechanically polished with 800 -grade abrasive paper and degreased in acetone in an ultrasonic bath before use. The geometrical surface of the steel electrodes was about $3 \mathrm{~cm}^{2}$.

A three-electrode cell with $50 \mathrm{~cm}^{3}$ volume was used for electrodeposition of PPy on the steel substrate. $\mathrm{Ag} / \mathrm{AgCl}$ (sat. $\mathrm{KCl}$ ) and platinum foil were used as reference and counter electrodes, respectively. The electrodeposition was carried out at room temperature, about $25^{\circ} \mathrm{C}$. The confocal laser scanning microscopy (CLSM) "Laser-Tech 1LD21D" was used for characterization of the defect created in the coating. The corrosion tests of the PPy-coated steel were carried out at $25.0 \pm 0.3{ }^{\circ} \mathrm{C}$ in $3.5 \mathrm{wt} . \% \mathrm{NaCl}$ solution in which the open circuit potential (OCP) was continuously recorded for 2 days.

\section{Results}

The bi-layered coating consisting of an inner PPy-PMo $\mathrm{PM}_{12}$ layer and an outer PPy-DoS layer was galvanostatically electrodeposited on the steel surface according to the procedure described in (10). The inner PPy layer was doped with $\mathrm{PMo}_{12} \mathrm{O}_{40}{ }^{3-}$ and $\mathrm{HPO}_{4}{ }^{2-}$ ions at the ratio 1.0:2.2 (9). The outer layer was doped with organic ions of DoS. The total thickness of the bi-layered PPy film was $4.2 \mu \mathrm{m}$ (10).

Before creation of the defect the coated steel was immersed in corrosion solution for 7 hours. It was supposed that a stable passivation oxide film at the metal-polymer interface was produced due to interaction between the polymer and the steel substrate. It was also supposed that $\mathrm{PMo}_{12} \mathrm{O}_{40}{ }^{3-}$ anions doped in the inner layer were partially decomposed to $\mathrm{MoO}_{4}{ }^{2-}$ and $\mathrm{HPO}_{4}{ }^{2-}$ according to the hydrolysis reaction.

$$
\mathrm{PMo}_{12} \mathrm{O}_{40}{ }^{3-}+12 \mathrm{H}_{2} \mathrm{O} \rightarrow 12 \mathrm{MoO}_{4}{ }^{2-}+\mathrm{HPO}_{4}{ }^{2-}+23 \mathrm{H}^{+}
$$

Since the decomposed forms of counter-anions are small compared with the original $\mathrm{PMo}_{12} \mathrm{O}_{40}{ }^{3-}$ ions, fast migration of the species to the defect was expected.

Figure 1 shows a 3D confocal laser scanning microscopy (CLSM) image of the defect created in the PPy film. The defect was created by pressing a wedge-shaped needle perpendicularly onto the sample surface. The defect reached the substrate steel, breaking down the passivation oxide film on the steel. This was confirmed by microscopic observation after removing the polymer film and polishing the steel surface. The area of the damaged zone on the steel was around $5 \times 10^{-3} \mathrm{~mm}^{2}$. 


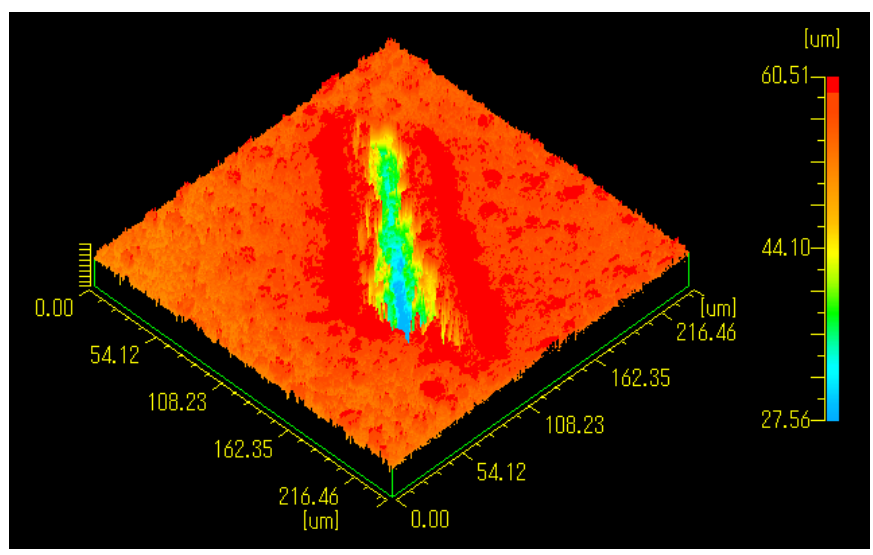

Figure 1. 3D confocal laser scanning microscopy image of the defect created in PPy film to expose bare surface of steel in a corrosion environment.

Figure 2 shows the change of OCP during the corrosion test in the $\mathrm{NaCl}$ aqueous solution as a function of time for steel covered by the bi-layered PPy film. In Fig. 2, a small defect was introduced on the coated steel after exposure for $7 \mathrm{~h}$.

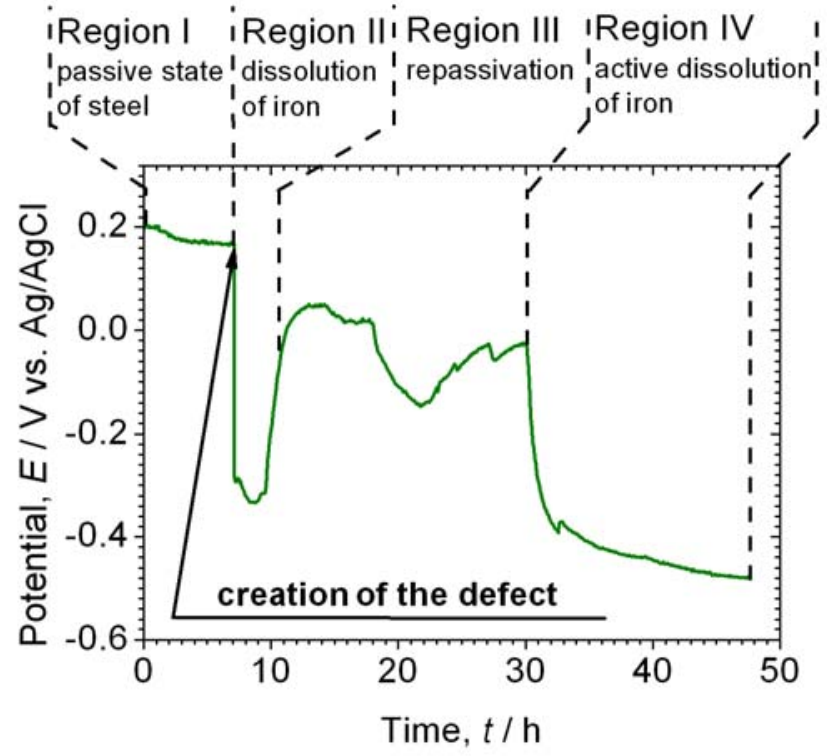

Figure 2. OCP as a function of immersion time for steel coated by bi-layered film of PPy$\mathrm{PMo}_{12} / \mathrm{PPy}-\mathrm{DoS}$ in 3.5 wt.\% $\mathrm{NaCl}$ aqueous solution. The defect was created in the coating after 7 hours of immersion.

The coated steel exhibits a potential around $+0.20 \mathrm{~V}$ to $+0.17 \mathrm{~V}$ before the introduction of the defect (region I). This relatively high potential indicates that the steel was passivated by the function of oxidative PPy. In this potential region no appreciable corrosion takes place. At 7 hours, when a defect was introduced in the coated steel, the potential changed to around $-0.30 \mathrm{~V}$. In this potential region the steel is activated and the dissolution of iron takes place. During the dissolution corrosion products are gradually observed on the coating surface around the damage (Region II). After 3 hours from creation of the defect, 
the potential increased, reaching $0.05 \mathrm{~V}$. The increase of potential was associated with the formation of a salt film resulting from the precipitation between ferrous and/or ferric ions and dopant anions leaching from the PPy film in the damaged zone. It is supposed that the salt film blocks further dissolution of the iron and allows the passivation oxide film to be rebuilt under it. While the potential is $0.12 \mathrm{~V}$ lower than that before the introduction of the defect, the potential still corresponds to the passive state of steel (Region III). The upand-down potential indicates that activation by the attack of chlorides and repassivation by molybdate anions leaching from the PPy film alternate in turn. After 30 hours of immersion, the potential started to rapidly decrease to the active potential region of steel and the PPy film lost the capability to maintain the passive state of steel and efficiently protect the steel against corrosion (Region IV).

When the area of the defect introduced in the PPy film was too large, repassivation corresponding to the Region III was not observed and the potential remained low, around $-0.3 \mathrm{~V}$ after the introduction of the defect (data not shown).

\section{Discussion}

The bi-layered PPy film consisting of an inner PPy layer doped with $\mathrm{PMo}_{12} \mathrm{O}_{40}{ }^{3-}$ $\left(\mathrm{PMo}_{12}\right)$ and an outer PPy layer doped with dodecyl sulfonate (DoS) exhibits a selfhealing property, spontaneously repassivating steel after introduction of a defect. The repassivation of the steel may be explained by the following mechanism (Fig. 3). Once a defect is introduced into the coated steel, it is directly exposed to the $\mathrm{NaCl}$ solution and dissolves. The $\mathrm{PMo}_{12}$ doped in the inner layer undergoes hydrolysis by the penetrating water, decomposing to phosphate and molybdate anions. The phosphate and molybdate anions are released into the damaged zone and then react with ferrous and/or ferric ions from the steel to form a salt deposit. The salt deposit gradually blocks the dissolution and facilitates the formation of the passivation oxide underneath the deposit, finally repassivating the substrate steel. Details of the mechanism will be published in another paper.
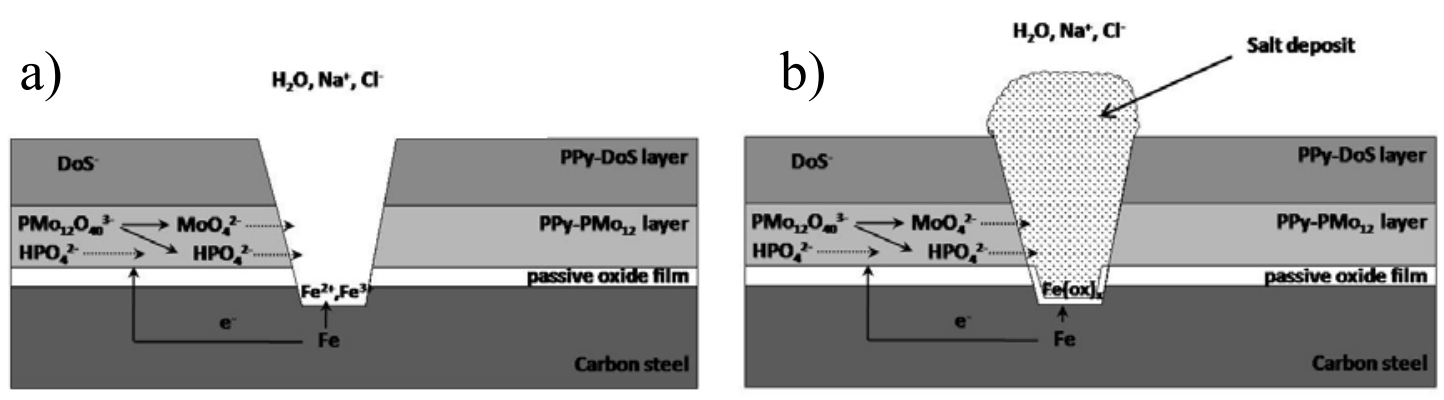

Figure 3. Mechanism of repassivation of steel by bi-layered PPy film with artificial defect: a) dissolution of iron, b) formation of salt deposit within the defect, and repassivation of steel.

\section{Conclusion}

The bi-layered PPy film consisting of an inner PPy layer doped with $\mathrm{PMo}_{12} \mathrm{O}_{40}{ }^{3-}$ $\left(\mathrm{PMo}_{12}\right)$ and an outer PPy layer doped with dodecyl sulfate (DoS) exhibited a self-healing property. When a defect was introduced into the PPy-coated steel, initial activation was 
followed by recovery of passivation. Without damage, the release of $\mathrm{PMo}_{12}$ doped in the inner layer was inhibited by the outer PPy layer doped with DoS. When the damage was introduced, the inner PPy layer released phosphate and molybdate anions to the damaged zone due to the decomposition via hydrolysis. Both anions work as passivation inhibitors and helped to repassivate the damaged zone on the steel.

\section{References}

1. Occupational Safety \& Health Administration (OSHA), Occupational exposure to hexavalent chromium; rules and regulations (29CFR1910, 1915 et al.) 39, 10103 (2006).

2. J. T. Kretchik, J. Chem. Health Safety, 13, 39 (2006).

3. D. W. DeBerry, J. Electrochem. Soc., 132, 1022 (1985).

4. B. Wessling, Adv. Mater., 6, 226 (1994).

5. W. K. Lu, R. L. Elsenbaumer, and B. Wessling, Synth. Met., 71, 2163 (1995).

6. M. Fahlman, S. Jasty, and A.J. Epstein, Synth. Met., 85, 1323 (1997).

7. T. Schauer, A. Joos, L. Dulog, and C.D. Eisenbach, Prog. Org. Coat., 33, 20 (1998).

8. J. He, V. Johnston-Gelling, D.E. Tallman, G.P. Bierwagen, and G.G. Wallace, J. Electrochem. Soc., 147, 3667 (2000).

9. D. Kowalski, M. Ueda, and T. Ohtsuka, Corros. Sci., 49, 1635 (2007).

10. D. Kowalski, M. Ueda, and T. Ohtsuka, Corros. Sci., 49, 3442 (2007).

11. D. Kowalski, Ph.D. thesis, Hokkaido University (2007). 